\title{
THE TEMPORARY MARKETING ORGANIZATION
}

\author{
Allègre L. Hadida \\ Cambridge Judge Business School \& Magdalene College \\ University of Cambridge \\ Jan B. Heide \\ Irwin Maier Chair in Marketing \\ School of Business \\ University of Wisconsin-Madison \\ Professorial Fellow, Department of Management and Marketing, University of Melbourne \\ Senior Research Associate, Cambridge Judge Business School, University of Cambridge
}

\author{
Simon J. Bell \\ Faculty of Business \& Economics \\ University of Melbourne
}

Forthcoming, Journal of Marketing

The authors contributed equally to the paper. They would like to acknowledge the helpful and constructive input from the Journal of Marketing review team. They would also like to thank Kevin Boudreau, Rodolphe Durand, Yves Evrard, Martin Kilduff, Alok Kumar, Ilkka Ojansivu, Anne Miner, Bernard Sinclair-Desgagne, Paul Tracey, Jennifer Wiggins, and seminar participants at HEC Paris for their helpful comments at various stages of this project. Finally, they would like to thank Professor Dame Sandra Dawson, Cambridge Judge Business School and Sidney Sussex College, University of Cambridge, for her role in facilitating this collaboration in the first place, and for her encouragement throughout the process. 


\title{
The Temporary Marketing Organization
}

\begin{abstract}
Increasingly, marketing activity is carried out within temporary organizations, where teams are assembled to complete a specific task within a predetermined timeframe. Such organizations are uniquely suited to promoting various marketing outcomes but are not well understood. From a practical standpoint, their inherent characteristics create organizational challenges which, if not appropriately managed, can compromise performance. Drawing on agency theory and research on embedded ties, we conceptualize these challenges in terms of particular selection and enforcement problems. We identify three different forms of temporary marketing organizations that vary in their selection and enforcement qualities. Next, we develop a conceptual framework which shows the selection and enforcement implications of a temporary organization's task, timeline and team composition. We also show how selection and enforcement mechanisms have portable qualities and can be "imported" to a given temporary organization, either from a prior temporary organization or from a larger permanent one.
\end{abstract}

\section{Keywords}

Temporary organization, agency theory, embeddedness, selection, enforcement. 
Marketing decisions and outcomes, for instance those relating to new product development, service delivery, and marketing communications, depend crucially on their organizational context. Past research has considered such decisions and outcomes within two main organizational contexts: (1) permanent firms (Day 1994; Ghosh and John 2005; Moorman and Day 2016), and (2) ongoing long-term relationships between firms (Dwyer et al. 1987; Jap and Ganesan 2000). Increasingly, however, marketing activity is being carried out within the context of temporary organizations, where the focal parties don't necessarily share a permanent structure or a long-term association. Temporary organizations are widespread in new product development (Brown and Eisenhardt 1995; Ibert 2004), business-to-business marketing (Tuli et al. 2007), and supply chain and channel design (Pfohl and Buse 2000). They are also increasingly popular in advertising, where campaign delivery requires the collaboration of diversely skilled specialists (Grabher 2002), and in the delivery of complex services like health care and tourism (Tax et al. 2013).

Industry observers have predicted that temporary organizations will be increasingly prevalent in meeting marketing objectives, given the pressure on firms to deliver innovative outcomes while simultaneously containing costs by outsourcing to external parties (Grabher 2004). New product development in the pharmaceutical industry, for example, has been all but devolved to temporary coalitions of universities, private labs, research centers, and IT firms, such that between 2000 and 2011, more than half of all new drugs approved in the United States were developed in "stand-alone entities" organized around particular drug discovery and commercialization (Myshko 2014). Resorting to temporary organizations can promote organizational agility which is, according to a 2017 McKinsey Global Survey, among the topthree priorities of business leaders (Ahlbäck et al. 2017). 
Yet, despite their apparent attractiveness, temporary organizations pose significant challenges, many of which are not readily accounted for by standard theory (Child and McGrath 2001). As a category, temporary organizations - described by some as the "organizational analog of a one-night stand" (Meyerson et al. 1996, p. 167) - are known for the "high variance" in their outcomes (Faulkner and Anderson 1987, p. 884). Some temporary organizations create products, services, or experiences that impress industry experts and delight customers. Others, in contrast, exceed their budgets, fall short of expectations, and are soon forgotten. As an organizational form, temporary organizations have been argued to possess unusual "liability of newness" problems (Nohria 1992). For example, upon winning the global communications business for Dell in 2007, holding company WPP built a new marketing communications temporary organization, 'Enfatico', from the resources of its existing agencies primarily to provide a high level of service to Dell. While enthusiastically conceived, this initiative ultimately faced a number of challenges and was folded back into the Y\&R agency two years later (Gralpois 2010).

We posit that the inherent challenges of temporary organizations, which contribute to their high variance property, follow from their discrete time dimension: namely, a lack of a distinct past and a future. With respect to the past, the outcome of a temporary organization hinges on the characteristics of its "motley crew" of members (Caves 2000, p. 5); many of whom may be working together for the very first time. From an organizational standpoint, this makes team selection a crucial undertaking; even more so than in other settings. Further, the outcome of a temporary organization's task depends on its members' efforts. Yet, in absence of a tangible future - many temporary organizations disband upon task completion - the inherent incentives for inducing member effort that characterize other organizational forms (Heide and Miner 1992) are lacking. In addition, for many temporary organizations standard mechanisms like member 
socialization (Chatman 1991) and long-term rewards (Holmstrom and Tirole 1989) are unavailable. As a consequence, temporary organizations face significant enforcement problems.

We develop a conceptual framework based on three forms of temporary organizations which differ in their selection and enforcement properties. Theoretically, the framework rests in part on the notion of portability (Groysberg et al. 2008), namely the idea that particular selection and enforcement mechanisms can be transferred from a given temporary organization's context, and thus be supplied (exogenously) to the temporary organization in question. For instance, a "hybrid" temporary organization (Schwab and Miner 2008) can draw on organizational qualities that reside in prior ties among its members, while a "fully embedded" temporary organization benefits from the properties of the permanent organization within which it exists and which can be brought to bear on discrete tasks. Grabher's (2002) analysis of the UK advertising industry shows how temporary organizations are embedded in "organizational and social layers" (p. 243). One of our key theoretical arguments is that if a given temporary organization, due such "layers", benefits from portable selection and enforcement benefits, it reduces the need for task-specific selection and enforcement efforts.

We seek to make four contributions to the literature. First, we document the unique characteristics and performance outcomes of an organizational form that is increasingly important to marketing. Given that marketing capabilities have a greater impact on firm performance than operational and R\&D capabilities (e.g., Krasnikov and Jayachandran 2008), there will be a premium on effective management of temporary marketing organizations. At the same time, this research also shows that marketing knowledge is inherently difficult to codify. This problem, we argue, is magnified in a temporary marketing organization. Unfortunately, as shown by recent reviews (e.g.,Lundin et al. 2015), the current knowledge about temporary organizations is both limited, and represented almost exclusively by scholars in engineering, organization theory, and 
general management. To date, marketing has contributed little. The current paper represents an initial attempt to join and inform this literature.

Second, we identify some of the specific selection and enforcement mechanisms available to temporary organizations. Organizational researchers (e.g., Bakker et al. 2016; Lundin et al. 2015) have commented on how insights into specific mechanisms are lacking in the literature, and on the tendency to view temporary organizations strictly as "tools" rather than as organizations in their own right (Packendorff 1995). As such, while our main focus is on temporary organizations in a marketing context, we believe that our conceptual discussion of selection and enforcement informs the general literature on temporary organizations.

Third, we integrate economic and sociological perspectives on temporary marketing organizations. Our model draws on agency theory (Bergen et al. 1992) and extant research on “embedded" ties (Granovetter 2005; Rindfleisch and Moorman 2001; Wuyts and Geyskens 2005) to suggest how a temporary marketing organization's selection and enforcement problems can be addressed. Both of these theories are uniquely suited to analyzing temporary marketing organizations, given their focus on mechanisms such as signals which don't involve permanent structures. We argue that the very logic of a temporary organization involves identifying inherent matches between members and tasks, rather than creating them through permanent structures. These theories, however, provide different perspectives on how matches come about, including the specific manners in which selection and enforcement take place.

Fourth, from a practical standpoint we propose a conceptual framework which suggests how particular exogenous drivers, namely a temporary organization's task characteristics, time frame, and team composition, give rise to (1) particular selection and enforcement needs, and ultimately (2) choices among types of temporary organizations. We also show how project managers and firms choose between making organization-specific governance choices vs. 
relying on pre-existing mechanisms that are portable from prior temporary organizations. We suggest how matches between exogenous drivers and organizational choices have performance implications, with regard to (1) the creativity of a temporary organization's output and (2) its decision-making speed. We illustrate our guidelines by drawing on examples from current practice.

In the next section, we discuss the nature of the temporary marketing organization, and identify the main forms that exist. Next, we introduce our conceptual framework. The final section summarizes the model, discusses managerial implications and provides critical paths for future research.

\section{The Nature of the Temporary Marketing Organization}

Based on the original contributions of Bennis (1965) and Goodman and Goodman (1976), a temporary organization is generally defined as a "temporally bounded group of interdependent actors formed to perform a complex task" (Burke and Morley 2016, p. 1237). "Temporally bounded" means that a temporary organization is initiated by the commitment to a certain task, and terminated by its completion; by the attainment of a particular state, or by reaching a predetermined timeline (Grabher 2002; Manning and Sydow 2011). In other words, a temporary organization is subject to "institutionalized termination" (Lundin and Söderholm 1995, p. 449) rendering it effectively "disposable" (March 1995, p. 427). The temporary organization members are individuals who collectively possess the skills and resources required to carry out the focal task. In agency-theoretic terms (e.g., Bergen et al. 1992; Turner and Müller 2003) these are "agents" who are assembled and managed by a "principal", namely the temporary organization's project manager. The principal could be the chief technology officer on an application development initiative, the chief marketing officer managing software developers and advertising 
agencies for the launch of a new brand, or a firm's CEO or CMO as they assemble a temporary organization within or outside the boundaries of their permanent organization. As shown by Tax, McCutcheon, and Wilkinson (2013), a customer may also serve as a temporary marketing organization's principal, by virtue of playing the role of a "resource integrator" (Vargo and Lusch 2008, p. 257) who assembles a team of service providers for a given task. ${ }^{1}$

\section{The 'Stand-Alone' Temporary Organization}

A "baseline" temporary organization has a discrete time horizon, and possesses neither a past nor a future. Indeed, the notion of discreteness, which in the extant literature (e.g., Schwab and Miner 2008) is sometimes captured by the term "stand-alone", is the "constitutive property" of a temporary organization (Sydow 2017, p. 200). Baseline "stand-alone" temporary organizations are quite common, for instance in advertising (Grabher 2002), high-technology systems selling (Möller and Rajala 1999), and supply chain design (Pfohl and Buse 2000).

In Table 1, we compare a stand-alone temporary organization to three other, more commonly discussed, organizational forms: namely, a joint venture, a start-up, and a permanent organization. ${ }^{2}$ A distinctive feature of a stand-alone temporary organization is a complete absence of both (1) a history of interaction between members, and (2) a possible future. At the other extreme, due to the employment relationship and ownership of internal divisions, a permanent

\footnotetext{
${ }^{1}$ Temporary organizations may exist that don't exhibit a standard hierarchical structure between a principal and an agent, or that exhibit more complex structures, such as multiple agency hierarchies. For instance, a temporary organization's manager may also be an agent vis-à-vis its owner (e.g., a financial investor), who then acts as principal (Turner and Müller 2003). The principal-agent relationship within a temporary organization may also shift over time. Thus, the agency partner who initially assembles a temporary organization under the impetus of the CMO of her client organization may delegate its management to one or several senior team members, who may take turns leading it at various stages. We are thankful to an anonymous referee for drawing our attention to such situations.

${ }^{2}$ In order to streamline the flow of our argument and to ensure comparability in our discussion, Table 1 only features the "baseline" case for each of these alternative organizational forms. We also appreciate that our comparative organizational forms in Table 1 are not exhaustive and that partnerships and alliances (i.e., organizational forms not involving long-term contracts and equity participation) share similarities with temporary organizations. Typically, however, alliance and partnership research focuses on a "formal agreement between two partners" (emphasis added, Parmigiani and Rivera-Santos 2011, p. 1117), while temporary organizations are concerned with agreements between multiple members.
} 
organization can rely on both a history and the promise of future interaction between members on multiple tasks. Joint ventures and start-ups occupy the middle ground between temporary and permanent organizations, and share certain features of each. For example, both joint ventures and start-ups are less enduring than permanent organizations, despite the general expectation of a future, as they are more prone to failure and premature termination (Gulati 1998). Start-ups also share with temporary organizations the absence of a history due, in part, to the novel tasks and market needs that bring together a unique group of organizational members. Neither joint ventures nor start-ups, however, exhibit the absence of both a past and a future.

\section{Insert Table 1 about here}

Consider next the specific organizational implications of a 'stand-alone' temporary organization. As noted, the members of such an organization have no history of previous interactions - they are true "interdependent strangers" (Meyerson et al. 1996, p. 169) who lack a collective memory (Orr 2014). This, in turn, implies a lack of first-hand information about potential members' attributes, and creates a need for explicit selection efforts on behalf of the organization's principal, who needs to identify, sometimes from scratch, the particular skills and knowledge bases required by the agents to complete the focal task. As an example, Tax et al. (2013) note the importance of systematic selection in the delivery of complex services, where customers expect "connected experiences" and coordinated efforts from teams of suppliers or agents. Frequently the focal agent skills are unobservable or associated with information asymmetry; a condition which opportunistic agents can purposely exploit, thus creating an adverse selection problem (Akerlof 1970; Flyvbjerg 2011). ${ }^{3}$

\footnotetext{
${ }^{3}$ Selection may also involve the interactions between the agents in question. Caves (2003) frames this question as the "O-Ring" property of temporary organizations, where each input must perform up to a certain level. Creating the
} 
Agency theory's account of selection involves a principal who creates opportunities for agent self-selection (Bergen et al. 1992; Spence 1973), and/or agents who send signals that serve as proxies for their underlying characteristics. These signals may involve costs to the agent which create a separating equilibrium, in that only "appropriate" agents have the incentive to post the required "bond" (Ippolito 1990). In general, the selection process in agency theory is taskspecific and forward-looking: it focuses on the unique selection efforts that are needed for the task at hand. This perspective is of particular relevance to a stand-alone temporary organization, which does not possess inherent or pre-existing organizational properties.

While selection efforts serve important organizational purposes, they are rarely sufficient on their own, in part because even the "right" agents may fail to fully use their skills (Kirmani and Rao 2000; Mishra et al. 1998). As such, explicit enforcement efforts are typically needed to mitigate ongoing moral hazard problems (Arrow 1985). A stand-alone temporary organization faces unique enforcement problems due to its discrete time horizon (Cattani and Ferriani 2008; Manning and Sydow 2011) which generates weak incentives for cooperation among its members (Axelrod 1984; Heide and Miner 1992). ${ }^{4}$ Consider, as an example, the stand-alone temporary product development organization created to build the True Story card game and mobile app. Its instigators followed strict parameters for involvement using artificial intelligence on the Foundry online platform to assemble freelancers, and communicated through messaging software. The True Story members "flash mobbed" solely to create the product, and promptly disbanded after the completion of this task (Scheiber 2017). The "shadow of the future" (Axelrod 1984; Heide

right matches and ensuring their continuation pose interesting problems in their own right (Chisholm 1997; Daskalaki 2010). However, analyzing them goes beyond the scope of this paper.

${ }^{4}$ Clearly, there is often a desire to continue a collaboration initiated by a temporary organization. Research shows, however, that continuity is contingent on various factors, including the focal organization's performance (Schwab and Miner 2008). Thus, a temporary organization has an uncertain future. 
and Miner 1992) was so remote in this case that the project leader even described fellow temporary organization members as "these faceless, nameless, nationless submitters" (Kessler 2017, para 18).

The lack of built-in enforcement mechanisms requires explicit or task-specific efforts. In agency theory, this involves a formal contract which specifies financial incentives and monitoring procedures (Jacobides and Croson 2001). A temporary organization poses unique challenges in this regard, because of the need to provide incentives in the presence of novel tasks and ambiguity with regard to individual agent contributions (Azoulay and Lerner 2013; Holmstrom and Tirole 1989). For instance, temporary organizations developing new products in the commercial aircraft industry (Shenhar et al. 2016) often use explicit revenue-sharing contracts which are designed to align the parties' interests.

\section{Hybrids and Fully Embedded Temporary Organizations: The Role of Context}

While a stand-alone temporary organization constitutes a useful baseline, research and empirical observation also point to other forms. Table 2 draws on Schwab and Miner (2008) to compare a stand-alone temporary organization to two other forms with respect to their past and future dimensions. The first line of the table shows a baseline stand-alone temporary organization. Next, we suggest how a temporary organization may "acquire" a past or a future, by virtue of (1) capitalizing on its members' prior relationships (a "hybrid" temporary organization), or (2) being embedded within a permanent organization where the focal members share a larger organizational context (a "fully embedded" temporary organization).

\section{Insert Table 2 about here}

In practice, a temporary organization's contextual influences may serve organizational purposes, with regard to how selection and enforcement are carried out. However, the specific 
nature of these influences, or, more generally, the manner in which temporary organizations interact with permanent structures (Sydow 2017), remains a largely unanswered question. In contrast to agency theory and its focus on individual transactions, embeddedness theory argues that economic transactions take place within social structures (Granovetter 1992) which allow for selection based on direct observation of past behavior. Specifically, embedded ties facilitate the transfer of fine-grained information (Uzzi 1997) which reveals parties' larger identities

(Granovetter 1992). These identities, in turn, may be relevant to a new temporary organization, and thus serve selection purposes. ${ }^{5}$

Further, the social content of embedded ties gives them inherent enforcement qualities (Krippner and Alvarez 2007). An agent's identity in an embedded relationship comprises more than skills and capabilities; it also includes solidarity with the other party (Durkheim 1933; Gulati and Gargiulo 1999) and thus helps to align the goals of the principal and agent (Ouchi 1980). ${ }^{6}$ This larger identity, in turn, serves as an ongoing source of motivation and self-control (Akerlof and Kranton 2010).

Consider first a "hybrid" temporary organization, where the parties have a history gained from interacting on previous tasks. Hybrid temporary organizations are common in feature film production, where the same parties often engage in repeated collaborations (Faulkner and Anderson 1987). A specific example of a hybrid is the constellation of firms and independent contractors involved with Boeing's ongoing product development of the 737 airplane, first

\footnotetext{
${ }^{5}$ This discussion points to one of the inherent challenges of a temporary organization: While a principal may have pre-existing agent relationships, the novelty of a temporary organization's task may call for a broad search to identify new agents with the necessary skills and resources (Reagans et al. 2004). In essence, "strong" prior ties are inherently limited with regard to information access (Granovetter 1973).

${ }^{6}$ Temporary organizations have been shown to possess distinct norms and to exhibit patterns of collective behavior (Scheiber 2017). As such, despite their discrete time dimensions, they are distinct from pure market transactions defined by their lack of social content, as described in Macneil's (1980, p. 12) famous example of "a purchase of unbranded gasoline, out-of-town, at an independent gas station, paid for with cash".
} 
launched in 1966 and since evolved over three generations, including nine major variants. A supplier's involvement in previous product development phases of the 737 would create a reasonable expectation of being selected for involvement in subsequent phases. In general, ongoing relationships between the same parties represent a source of stability (Taylor and Levitt 2007). More specifically, as shown in Table 2, past interactions have organizational implications due to direct observation of a partner's behavior, and to the presence of relationship-level reputations and dyad-level norms which can be brought to bear on a new temporary organization.

Starkey et al. (2000, p. 299) have described a hybrid temporary organization as a "latent organization", because of the parties' ability to activate prior relationships (Lundin et al. 2015). At the same time, just like their counterparts in a stand-alone temporary organization, the members of a hybrid temporary organization don't necessarily expect to cooperate again after task completion. For instance, with more radical innovation in the Boeing product line (e.g., the 787 Dreamliner), members are far less certain of being involved in future product development tasks (Shenhar et al. 2016).

The third form is a "fully embedded" temporary organization, which exists within the boundaries of the permanent organization to which its members belong (Bakker et al. 2016). This form of temporary organization may possess some of the dyadic properties of a hybrid, to the extent that the same parties may be involved in successive temporary organizations. A fully embedded temporary organization also benefits from the aggregate features of the permanent organization itself, including organizational-level reputations and norms. As will be discussed, these features have particular selection benefits. Moreover, by virtue of being part of a permanent organization, a fully embedded temporary organization possesses a distinct future time horizon and a "probability of continuing association" (Demsetz 1988, p. 155). This time horizon provides enforcement benefits even in the absence of direct interactions between parties. Cremer (1986, p. 
34), for instance, notes the disciplinary effects that "the perpetual presence of tomorrow" has on organizational members. Even if discrete temporary organizations are formed and dissolved on an ongoing basis, common ownership may influence their members' actions, by allowing them to project beyond the completion of a given task.

These questions are the focus of recent research on the implications of the post-project “afterlife" for the principal-agent relationship (Ojansivu et al. 2013). Consider, for example, Ford Motor Company's development of the 1992 Lincoln Continental (e.g., Roth and Kleiner 2000). While organizing product development around temporary teams was becoming the norm in North American automotive manufacturing at the time, expectations of post-project interaction were limited by members' strongly-held "assumptions of their job description" (Ayas and Zeniuk 2001, p. 66) and narrow understanding of the product development process. Yet, in reality, members of the Lincoln team remained in contact even as they "were reassigned to other projects" (Ayas and Zeniuk 2001, p. 68).

As shown in Table 2, in addition to its built-in future, a fully embedded temporary organization has a set of explicit enforcement mechanisms at its disposal (Che and Yoo 2001; Williamson 1975; Zenger 1994), including low-powered incentives (e.g., promotion opportunities, non-monetary rewards), and centralized authority and monitoring mechanisms (Coase 1937). Grant (1996) notes how low-powered incentives help promote cooperation among specialists; a common scenario within fully embedded temporary organizations. In the section below, we discuss how different selection and enforcement mechanisms match up with particular exogenous influences or drivers to impact a temporary organization's performance. 


\section{A Conceptual Framework of the Temporary Marketing Organization}

Our conceptual framework is shown in Figure 1. We first introduce its main components and linkages. Next, we discuss some of its underlying micro-level processes, and develop a set of propositions.

\section{Insert Figure 1 about here}

The framework's starting point is a series of “drivers" or exogenous influences which create governance problems of various kinds. We draw on past research on temporary organizations (Jacobsson et al. 2013; Lundin and Söderholm 1995) to focus on three specific manifestations of the so-called "Ts", namely, task, time, and team. These are the novelty of the organization's focal task, its planned duration, and the composition (or heterogeneity) of its team. ${ }^{7}$ As shown in Figure 1, the effects of the three exogenous drivers on the choice of temporary organization form are mediated by the particular selection and enforcement problems which they give rise to.

Theoretically, these particular theoretical linkages assume that organizational form matters. In part, this is because, as discussed, organizational forms possess inherent governance mechanisms, such as the social fabric of a hybrid and the long-term rewards of a fully embedded temporary organization. As such, the need for a certain governance mechanism (e.g., a particular enforcement mechanism) impacts the choice of organizational form.

\footnotetext{
${ }^{7}$ We acknowledge that this is not an exhaustive set of drivers. Jacobsson et al. (2013), for instance, discuss a fourth " $t$ "; namely, transition. Transition, however, has more to do with the transformation that takes place during the lifespan of a temporary organization (e.g., from idea to full-fledged marketed product and from temporary structure to becoming embedded within a permanent organization) than with an exogenous driver per se. We also note that the drivers may be related among themselves. For instance, the nature of a temporary organization's task may determine the composition of its team. We will show, however, that each driver poses unique governance challenges.
} 
Further, as shown by the backward-pointing arrow in the figure, we allow for the possibility that context matters, and that an existing temporary organization, either in the form of a hybrid or a fully embedded one, may make certain selection and enforcement benefits available to a new one. Under such a scenario, pre-existing governance mechanisms are portable across organizational contexts, and can be brought to bear on a new temporary organization.

The last part of the conceptual framework describes a temporary organization's performance outcomes. We capture performance outcomes through output creativity and decision-making speed. Our general expectation, as expressed by the dotted line which frames the model in Figure 1, is that performance follows from matches between (1) the exogenous drivers and (2) the organizational choices made. Conversely, as will be discussed, we expect that mismatches will undermine performance.

\section{Drivers, Governance Mechanisms, and the Choice of Temporary Organization Form}

Task. A temporary organization's task has been argued to represent its "reason for being" (Lundin and Söderholm 1995). Our particular focus is on novel tasks, where a temporary organization is assembled for the purpose of executing a "one-off, non-routine" task (Gann and Salter 2000). Such initiatives are characterized by causal ambiguity (Thompson 1967), in that the principal does not clearly define the goals nor the means to reach them at the outset (Holmstrom and Milgrom 1991; Lenfle and Loch 2010). For instance, x, a highly confidential R\&D facility founded in 2010, allows its parent company Alphabet to assemble temporary organizations dedicated to developing "moonshot" new products with no direct link to Google's core business of internet search. They include energy kites, salt-based energy storage and floating internet routers (https://x.company/, accessed 4 October 2018).

Truly novel tasks require distinctly novel human and technological resources that may not be available from prior relationships or within an existing firm, and therefore call for the 
principal to search from a new agent pool. Levitt et al. (1999) specifically describe how nonroutine activities tend to involve individuals (for instance, advertising agents or marketing consultants) who lack experience working together, even though they may share common industry or disciplinary knowledge.

For the above reasons, we expect task novelty to be best addressed by a stand-alone temporary organization, albeit subject to organization-specific selection and enforcement efforts which safeguard against subsequent difficulties. In the case of True Story, the careful algorithmbased selection of contributors, and the clear specification of their roles in the development of the game, contributed to mitigating such difficulties and enabled them to discharge their responsibilities effectively. However, when the unique nature of the task led to some substandard deliverables, the principal intervened to solve the problem by hiring "another freelancer ... to oversee this work" (Scheiber 2017, p. 4).

We expect hybrid and fully embedded temporary organizations to be more constrained vis-à-vis novel tasks, because both involve selection from a pre-existing, and thus limited, pool of agents. Familiar tasks, however, create a different scenario: For such tasks, "members know what to do, and why and by whom it should be done" (Lundin and Söderholm 1995, p. 441). Agent requirements can be unambiguously spelled out ex ante in a way that facilitates selection, and enforcement can be carried out through standard agency devices like monitoring, potentially against the backdrop of a formal contract (Grossman and Hart 1983). Agents' general industry roles and reputations may also serve monitoring purposes (Bechky 2006; Turner and Müller 2003). Thus, for familiar tasks the relatively modest selection and enforcement requirements make a hybrid or fully embedded temporary organization feasible. We propose the following:

Proposition 1: The greater the novelty of the task, the greater the need for organizationspecific selection and enforcement mechanisms, and the higher the 
likelihood of using a stand-alone temporary organization relative to hybrid and fully embedded forms.

Time. Time is a second critical driver of a temporary organization's governance needs (Lundin and Söderholm 1995). Importantly, while all temporary organizations share the characteristics of a fixed start and ending point, their planned duration varies considerably. We focus on differences in duration and their governance implications. Specifically, time limits create a sense of urgency and place a premium on selecting appropriate partners and quickly deploying enforcement mechanisms. For instance, creating a music video takes as little as two days (Bechky 2006). Such a time frame makes it virtually impossible to craft organizationspecific enforcement mechanisms like social norms, and it may be necessary for the principal to draw on an existing network where agents' reputations from direct interactions (1) serve informational and enforcement purposes and thus (2) represent functional substitutes for new or organization-specific mechanisms.

Arguably, the need for speed provides an incentive to search for agents internally, and thus to resort to a fully embedded temporary organization. Doing so, however, may come at the expense of (1) acquiring truly new knowledge [as per Granovetter's (1973) tie strength thesis], and (2) identifying partners with skills that match the focal task. In essence, embedded ties from prior direct interactions - that is, the "shadow of the past" from previous exchanges - are better suited to provide portable selection and enforcement benefits that can be applied to a new task. Importantly, such benefits are not necessarily available from a fully embedded temporary organization where the focal parties, while belonging to a common permanent organization, may not have had direct prior interactions with each other. ${ }^{8}$ In proposition form:

\footnotetext{
${ }^{8}$ We acknowledge that repeated ties may take place between members of the same permanent organization. If so, the temporary organization in question would be the equivalent of a hybrid, due to the direct (rather than indirect)
} 
Proposition 2: The shorter the duration of the task, the lower the feasibility of crafting organization-specific selection and enforcement mechanisms, and the higher the likelihood of using a hybrid temporary organization relative to stand-alone and fully embedded forms.

Team. A third driver of a temporary organization's governance needs is its team composition (Lundin and Söderholm 1995) conceived, in our context, as the heterogeneity of its members. Heterogeneity presents a number of organizational challenges, perhaps the most important of which being the need to coordinate action and manage potential conflict (Gulati et al. 2012). In these respects, we expect the fully embedded form of temporary organization to possess inherent benefits relative to the stand-alone and hybrid forms.

The high-powered incentives that characterize the stand-alone and hybrid forms serve to emphasise and "separate the interests of the agents" which may exacerbate underlying conflict within the temporary organization. The implicit and low-powered incentives characteristic of fully embedded temporary organizations, by contrast, serve to "interlock the fates of agents" via the employment relationship and, thus, reduce potential sources of conflict within the temporary organization (Che and Yoo 2001, p. 538). Further, an employment relationship gives rise to member expectations of mobility within and between teams within the permanent organization (Dougherty and Takacs 2004). Thus, in the event of potential conflict arising from heterogeneity, the principal can substitute and redeploy temporary organization members efficiently. In practice, the inherent characteristics of a fully embedded temporary organization possess unique selection and enforcement benefits that address the problems that arise from team heterogeneity.

Proposition 3: The greater the heterogeneity of the team, the greater the need for enforcement through low-powered incentives, and the higher the likelihood of using a fully embedded temporary organization relative to hybrid and stand-alone forms.

association between the relevant parties. We note, however, that there are qualitative differences between internal and external transactions (Akerlof and Kranton 2010). We return to this question in the Discussion section. 


\section{Portability and Exogenous Selection and Enforcement Effects}

As discussed, our framework is based in part on the possibility that the selection and enforcement needs of a temporary organization may be portable or supplied exogenously, either from pre-existing agent relationships (in the case of a hybrid temporary organization), or from the features of a permanent organization (in the case of a fully embedded one). Albeit not entirely infeasible, portability is much less achievable in the case of a stand-alone temporary organization, which benefits neither from prior agent relationships nor a common permanent organization.

Consider first the case of a hybrid. Past research has identified patterns of repeat encounters across temporary organizations through "persistent semi-permanent work groups" (Blair et al. 2001). Such interactions reduce information asymmetry due to (1) first-hand observation of agent attributes (Gulati et al. 2009), and (2) knowledge sharing between members about agent abilities (Grant 1996). As such, prior relationships serve potentially important selection purposes. With regard to enforcement, a pre-existing tie is capable of aligning parties' goals (Ouchi 1980), which in turn promotes agent effort and reduces the need for explicit incentives and monitoring. For example, for the development of subsequent generations of the 737 airplanes, Boeing, "reluctant to upset the delicate balance", have tended to draw on familiar components suppliers for model upgrades, a fact made possible by a high percentage of immutable and familiar features of the 737 product (Aaronson et al. 2016, p. 4). This suggests that enforcement benefits may also be portable.

As noted, hybrid temporary organizations represent sources of knowledge (Grant 1996), pertaining specifically to an individual agent and her capabilities (Krasnikov and Jayachandran 2008) and motivation. Importantly, however, there are limits to the transferability of such knowledge. Stated differently, the portability that resides in prior relationships is subject to 
boundary conditions. As we discuss below, these boundary conditions reside in the temporary organization's task.

Consider first selection, and how novel tasks limit portability. As an example, consider how many established firms are experimenting with temporary innovation labs to leapfrog (or, at the very least, keep pace with) industry upstarts in order to cope with faster innovation cycles and the threat of business model disruption (Davies and Hobday 2005; Grabher 2004). The example of X, noted earlier, provides an illustration of such experimentation, as does Spanish telecommunications company Telefonica, which set up a temporary innovation lab in Cambridge, UK, to work on the development of new products for Internet-of-Things (IoT) and wearable devices. The lab sat outside regular technology management and compliance processes at Telefonica but drew on established networks of agents, including Spanish engineers and longtime partner MediaTek - a Taiwanese semiconductor design company - which housed the lab in its $R \& D$ offices.

A principal's past interactions with individual agents reveal particular agent traits. However, given a new task these traits are not automatically portable (Huckman and Pisano 2006). Past interactions may have demonstrated "technically competent role performance" (Meyerson et al. 1996), but it's not a given that such information transfers readily to a new temporary organization with unique requirements (Schwab and Miner 2008). Theoretically, we posit that embedded ties are limited in their ability to address adverse selection problems which arise with new tasks. Grabher (2002) specifically discusses how some temporary organizations face significant selection problems because of the limited signaling value of general governance mechanisms like industry certification and professional codes.

At the margin, a pre-existing tie may increase an agent's tendency to truthfully represent her attributes to the principal, but this in itself may have a limited effect on a temporary 
marketing organization's performance. In practice, this means that for selection purposes in the context of novel tasks, the information that is naturally available to a hybrid must be augmented with explicit (endogenous) signals that reveal the necessary agent traits. At very high levels of novelty, the advantages of portability might diminish to the point that it makes more sense for the firm to abandon a hybrid approach, reverting to a stand-alone model of temporary organization and benefiting from searching a completely new, and larger, pool of agents..$^{9}$

As a specific example, Boeing, in the development of the radically different 787 Dreamliner, had to adopt a new organizational model to recruit a large number of new and existing partners who were responsible for an "unprecedented portion of the design" (Shenhar et al. 2016, p. 63) - design skills that Boeing lacked due to the inclusion of new technologies that had not been used before in such large civilian aircraft. This required the development of specific incentives deployed (endogenously) for the new product development organization. In particular, Boeing asked its suppliers to self-select for a "build-to-performance" risk and revenue sharing model unique to the Dreamliner development task, in which suppliers bore the upfront cost of R\&D but shared in revenues from future aircraft sales. Thus, we suggest that hybrid (embedded) ties and formal (agency-based) signals are not functional substitutes for each other. Rather, they address different types of problems, and may serve complementary purposes. In proposition form:

Proposition 4: The greater the novelty of the task, the lower the portability of the selection benefits from a hybrid temporary organization, and the greater the need for organization-specific selection mechanisms.

\footnotetext{
${ }^{9}$ The reversion to a stand-alone form at high levels of novelty, and the selection and enforcement efforts this form requires, is captured in Proposition 1.
} 
A pre-existing tie with a particular principal also impacts an agent's general motivation to support the focal relationship (Uzzi 1997). As such, we posit that the enforcement properties of a hybrid tie (Krippner and Alvarez 2007) are portable across temporary marketing organizations, regardless of the nature of the task. Thus, perhaps counter-intuitively, the enforcement effect of a hybrid tie has a broader scope than its selection effect, and inferences about likely agent effort transfer more readily across individual temporary organizations. In practice, to the extent that a hybrid tie has portable enforcement qualities, it serves as a functional substitute for formal agency mechanisms like financial incentives and monitoring. Corts and Singh's (2004) research specifically suggests that repeated interaction between parties is capable of solving incentive problems. In formal terms, while hybrid ties possess limitations vis-a-vis adverse selection problems, they may, because of their general effects on agent motivation, serve as solutions to moral hazard problems. We propose the following:

Proposition 5: For a hybrid temporary organization, enforcement benefits are portable regardless of the nature of the task.

Finally, consider portability in the context of a fully embedded temporary organization. Here, the features of a permanent organization confer potentially portable selection and enforcement benefits to the temporary organization. As with hybrids, we expect portability to be task-dependent: For familiar tasks, we expect that a fully embedded temporary organization's selection and enforcement benefits will both be portable. For novel tasks, however, we expect only the enforcement benefits to be portable.

Importantly, while our expectations for hybrids and fully embedded temporary organizations parallel each other, the underlying explanatory mechanisms (and the specific sources of portability) are different. In the case of a hybrid temporary organization, the portable 
selection benefits (for familiar tasks) rest on direct interaction and personal reputations between principals and agents. These, in turn, make information about a partner's motivation to perform available from personal experience. This defining feature of a hybrid temporary organization is not necessarily present in a fully embedded temporary organization, where the parties, while belonging to the same permanent organization, may not necessarily have interacted directly in the past.

As a result, the selection benefits for a fully embedded temporary organization involve general agent reputations that reflect a firm's standard “experience ratings" (Williamson 1975), but which may not be based on direct interactions between the focal parties. Further, the portable enforcement benefits of a hybrid are rooted in particular dyadic norms cultivated from direct contact between parties. While a fully embedded temporary organization possesses unique enforcement mechanisms like low-powered incentives (e.g., in the form of promotion opportunities and fixed financial compensation) that serve enforcement purposes (Grant 1996), we believe that these mechanisms, due to their general and non-personal nature, are weaker than the dyadic norms that characterize a hybrid. Team members working in the Lincoln Continental (fully embedded) temporary organization, for example, contributed to a series of "process innovations" and built "communities of practice" that united them under a common mission (Ayas and Zeniuk 2001, p. 67). While highly attractive organizational features, they were less likely to survive the disbanding of the temporary organization as the "immune system of the larger company" made it more difficult for learning to permeate beyond the team at project completion (Ayas and Zeniuk 2001, p. 67). Accordingly, we propose the following:

Proposition 6: The portability of a fully embedded temporary organization's selection and enforcement benefits is weaker than for those of a hybrid. 


\section{Performance Outcomes of the Temporary Marketing Organization}

Our first six propositions are descriptive in nature, in that they illustrate the likely (as per extant theory) organizational choices made by firms. We note, however, that the theories that we relied on to derive Propositions 1 to 3 (e.g., agency theory) have explicit normative underpinnings. As such, organizational choices that are consistent with these propositions represent "matches" that should manifest themselves on specific performance dimensions including, as per the extant literature (e.g., Levitt et al. 1999; Shenhar 2001), a temporary organization's impact on the end customer. Such impact may include output creativity, as reflected in whether a temporary organization's output, for instance a new advertising campaign or product, differs from competing alternatives in a way that is meaningful to customers (Dewar and Dutton 1986). Further, a match may impact decision-making speed, or the time elapsed between the initial idea generation and the deployment of the focal campaign or product launch. In the following we explore how matches between the nature of a temporary organization's task and its selection and enforcement requirements affect output creativity and decision-making speed, respectively - two outcomes that are particularly relevant to marketing. ${ }^{10}$

Output creativity, we argue, is inherently linked with selection efforts. To the extent that a given selection process succeeds in identifying a "motley crew" (Caves 2000) of agents with an appropriate set of skills (a "match" scenario), it should produce an output with novel attributes, such as a new product or service that achieves a desired location in some multi-attribute space (Ghosh and John 2012). Research shows, for instance, that groups in which experienced members are appropriately matched with new ones produce more innovative outcomes (Perretti and Negro

\footnotetext{
${ }^{10}$ For space reasons, we limit ourselves to explicating the performance relationships (matches and mismatches) that involve task characteristics (i.e., novelty).
} 
2007). Thus, selection efforts that match the temporary organization's novel task requirements can be expected to have performance implications in the form of output creativity. ${ }^{11}$

Conversely, "mismatches", or observed deviations from the stated propositions, can be expected to undermine performance. We consider two types of mismatches: First, a temporary organization's actual selection and enforcement efforts may fall short of the requirements set forth in our framework for a required level of task novelty. Suppose, for instance, that a principal erroneously assumes that an existing agent relationship has complete portability and, based on that assumption, fails to undertake the explicit selection efforts that the new task requires. Theoretically, this would produce an adverse selection scenario (Akerlof 1970), in that agents who lack the necessary creative skills for the task are chosen. In practical terms, such an organization would be "underorganized" (Chen 2009) relative to the task at hand. Ultimately, output creativity would be compromised by the insufficient selection efforts. Davies and Hobday (2005) provide case evidence which suggest how customer-level outcomes like satisfaction may be undermined by mismatches between a temporary organization's particular needs and the structures that are deployed to produce such outcomes.

In the second type of mismatch, the organizational choices that are made in a given situation may produce a temporary organization that is "overorganized", in that the mechanisms in question are redundant given the temporary organization's actual needs. This could be a result of underestimating the organizational qualities that reside in a temporary organization's larger context. For instance, unlike the logic underlying Proposition 1 that novel tasks require a standalone temporary organization and new (task-appropriate) skills, a firm may fall back on an

\footnotetext{
${ }^{11}$ This presumes that the relevant skills are actually deployed or applied to the focal task, in order to ensure the conversion (Chandy et al. 2006) from an initial idea or concept to an end product (e.g. a marketed product or a campaign).
} 
existing structure and rely on a fully embedded temporary organization. For a truly novel task, this would involve a mismatch, to the extent that the necessary skills are unavailable internally. Ultimately, sought-after creativity outcomes may be compromised. The above discussion suggests the following proposition:

Proposition 7: The closer the match between the novelty of a temporary marketing organization's task and its selection efforts, the greater the creativity of its output.

Proposition 7 will hold, in principle, for matched selection efforts across all forms of temporary marketing organizations. However, absolute levels of output creativity might differ across forms. In a stand-alone temporary marketing organization, information about member motivation is indirect, but the pool of potential candidate organizations is unlimited (in terms of ability). For a hybrid, on the other hand, information about motivation is more abundant and direct, yet the principal must draw from a limited agent pool (in terms of ability). Further, McDonald and Westphal (2003) identify the possibility of information-processing biases resulting from strong pre-existing ties (as in the case of a hybrid) which cause principals to settle for suboptimal agent relationships, revealed by a tendency to attach greater weight to collaborative rather than technical skills (Casciaro and Lobo 2005). Taken together, hybrid temporary marketing organizations will on balance produce less creative output than stand-alone temporary marketing organizations.

Consider next the performance implications of decisions with regard to enforcement. Enforcement, we argue, is inherently linked with a temporary organization's decision-making speed. As an example, in the context of new product development, speed is reflected in a given product's time to market, as measured by the time elapsed between the initial idea stage of a product development process and the actual market launch (Fang 2008). In the context of 
advertising, speed has to do with how quickly a campaign can be deployed that responds to key cultural events, political activities, or competitive actions (Grabher 2002).

To the extent that appropriate enforcement efforts have successfully aligned parties' objectives (e.g., through explicit incentives), the lower the friction in the organization's decisionmaking processes, and the more quickly the focal campaign or product can be launched. In general, aligning objectives helps develop blueprints for action (Eisenhardt and Tabrizi 1995) which lead to efficiency by "preventing deviation" (Ulset 1996, p. 70). Where conflict does emerge between partners, it can be resolved quickly according to these predetermined protocols (Bstieler and Hemmert 2010) that increase decision-making speed.

On the flip-side, mismatches are likely to undermine decision-making speed. If a firm relies on a stand-alone temporary organization under conditions of low task novelty, they will be wasting time searching for, and socializing, new organizational members when a deployment of internal staff would suffice. Further, the stand-alone temporary organization's lack of built-in governance features will mean it is underorganized for the task at hand, which will reduce speed.

Decision-making speed may be also compromised by relying on mechanisms that are not strictly needed given the nature of the task. Assume that a given principal chooses to rely on formal incentives and monitoring, as per agency theory. To the extent that a prior relationship (in the case of a hybrid) would have provided sufficient enforcement benefits, the overorganization represented by the new agency mechanisms imposes significant set-up costs for an enforcement regime that is ultimately redundant (Rowley et al. 2000). In fact, overorganization may have negative consequences in the form of agent reactance (Brehm 1966) which "crowds out" intrinsic motivation (Deci et al. 1999; Heide et al. 2007; John 1984). Given that temporary organizations often (1) involve tasks that require high levels of intrinsic motivation (Cattani and Ferriani 2008; Osterloh and Frey 2000), and/or (2) employ professional service providers (Greenwood and 
Empson 2003; von Nordenflycht 2010) who value discretion and freedom from external constraints (Teece 2003), reactance scenarios are not unlikely and, thus, will significantly slow a temporary organization's decision-making speed. Stated formally:

Proposition 8: The closer the match between the novelty of a temporary marketing organization's task and its enforcement efforts, the greater its decisionmaking speed.

Propositions 7 and 8 recognize the natural linkages between (1) selection efforts and output creativity and (2) enforcement efforts and decision-making speed. Yet, they leave somewhat open the possibility of other linkages, namely between (1) selection efforts and decision-making speed and (2) enforcement efforts and output creativity. Consider, for example, the latter case. Enforcement fulfils the purpose of aligning goals between temporary organization members and eliminating friction in the relationships between them. As per Proposition 8, these actions result in greater decision-making speed. It might be argued, however, that matched enforcement efforts - to the extent that they get everyone 'on the same page' - suppress output creativity by virtue of promoting homogeneity within the organization (Horwitz and Horwitz 2007).

\section{Discussion}

Temporary organizations are increasingly used to carry out marketing activity. However, they tend to be "high variance" phenomena (Faulkner and Anderson 1987, p. 884) and their outcomes are uncertain. The initial premise of this paper was that identifying (1) the specific sources of variance, and (2) particular solutions requires a multi-theoretical perspective on how a temporary organization's set of agent inputs translates into outcomes. 
Our framework points to the risk of analyzing temporary organizations through a single theoretical lens. Agency theory's focus on individual contracts downplays the organizational qualities that may reside in prior ties and a common organizational context. At the same time, overestimating the organizational properties of the larger context may create problems in its own right, to the extent that the focal properties may not be fully portable. In general, temporary organizations face significant and partly competing demands (Schreyögg and Sydow 2010); some of which have to do with simultaneously managing pressures towards both under- and overorganizing (Chen 2009).

Past research, such as Granovetter's (2005) embeddedness thesis, has made a persuasive case for the "interpenetration of economic and social action" and for the need to jointly examine formal and informal organizational mechanisms (Cao and Lumineau 2015; Kumar et al. 2011). Our framework points to specific inter-relationships between embedded ties and formal agency mechanisms. For selection purposes, we argue that the two may complement each other, since explicit signals that reveal agent traits may sometimes be needed to augment pre-existing ties. In contrast, embedded ties may substitute for formal selection devices (Grugulis and Stoyanova 2012), but only for familiar tasks where agent traits are portable. Furthermore, embedded ties and formal agency mechanisms may substitute for each other as enforcement devices, regardless of the novelty of the temporary marketing organization's task.

In general, we seek to add precision to the embeddedness argument by suggesting that embedded ties possess particular, but to date undocumented, boundary conditions. Below, we first identify some implications for managerial decision-making that follow from our framework. We close with a discussion of topics for future research. 


\section{Managerial Implications}

While our current contributions are mainly theoretical, we nonetheless consider some broad prescriptions for managerial decision-making. As a starting point, in an era of shrinking marketing departments and shortened average tenure of CMOs (Tadena 2016), marketers are more inclined to rely on temporary organizations to meet their objectives with immediate impact. Some guidance about how best to implement this organizational form is therefore essential. We consider the development of guidelines to help firms determine the most appropriate selection and enforcement mechanisms depending on the form of temporary marketing organization to be the single most important managerial implication deriving from our framework. Using task novelty, time pressures, likely team heterogeneity, and temporary organizational form as inputs, we suggest building a 'playbook' to assist marketers in using temporary organizations to best effect. $^{12}$

To begin with, firms might audit the extent to which they have access to embedded networks of partners to complete the task at hand and meet its objectives. For instance, a simple starting point might be to count the number of formal agreements a firm has with external parties (e.g., licensing, joint ventures) and the extent to which it tends to engage in single partner alliances with multiple contractual agreements. Such assessments are likely to give a rough indication of how embedded a firm is within a network (Stuart 1998) and of the availability of pre-existing agent relationships. A more analytically rigorous approach would be to capture how well an individual, team, or firm is tied to well-connected others in a supplier network (Packard

\footnotetext{
${ }^{12}$ We concede that our 'playbook' may risk oversimplifying some of the nuanced interactions between the "Three Ts" as determinants of temporary organizational form. For example, some novel tasks may require more heterogeneous teams, resulting in a tension between the utility of stand-alone and fully embedded forms. Some degree of managerial judgement will be necessary to determine which project feature will dominate the choice of temporary organization form.
} 
et al. 2016). Eigenvector centrality (Bonacich 1987), for example, measures the extent to which an individual, team, or firm has relationships with suppliers who are themselves connected to many others - a reflection of the density of the network in which the focal firm is embedded.

An initial, systematic assessment of task novelty, time allocated to complete the task, and the likely composition of the team are equally important to a managerial application of our framework. Task novelty might reflect the amount of change expressed, for example, as a percentage of new or different elements involved in a task between the last similar task and the current one (Griffin 1997). It is an approach similar to Clark and Fujimoto's (1991) measure of project scope as an indexed combination of the number of newly designed elements and the level of supplier-controlled input. Experienced managers will have an intuitive sense of a task's time requirement - usually as a result of track record and industry benchmarking. Even so, industry research suggests that the majority of new product launches tend to experience delays (Wu et al. 2004), hinting at a general lack of ability to estimate task duration. This is where more sophisticated time tracking software similar to the ones used in the legal industry to estimate and track project time might assist. Finally, managers seeking to estimate in advance the optimal heterogeneity when assembling a team might borrow from some of the advances in relational demography. Salient (potential) team member characteristics might be used to calculate a Herfindahl-Hirschman coefficient (Blau 1977) which generates a single index of team diversity. Taken together, these diagnostics of embeddedness and task novelty, duration, and team heterogeneity can guide the design of temporary marketing organizations with the explicit goal of ensuring matches that promote sought-after marketing outcomes, including output creativity and decision-making speed. 


\section{Directions for Future Research}

We identify four broad avenues for future research, namely, (1) different forms of temporary organizations, (2) structural embeddedness, (3) multi-level relationships, and (4) micro-level properties and processes.

Forms of temporary organizations. A first area of future research focuses on identifying more fine-grained temporary organization forms. Our framework treated hybrid and fully embedded temporary organizations as separate categories, and we highlighted characteristics that are uniquely associated with each one (e.g., dyadic versus organization-level norms). Thus, in the discussion leading to Proposition 6, we focused on the unique incremental properties of a fully embedded temporary organization. We acknowledge, however, the possibility of overlap between categories, in that hybrids may take place within permanent organizations, and that the same individuals may interact with each other, either on different hybrids or on different temporary organizations within a given firm. This raises interesting theoretical questions regarding the relationships between different organizational mechanisms and whether they support or undermine each-other; and regarding whether the unique characteristics of a permanent organization support or undermine the particular properties of a hybrid.

Regarding the former, while the embedded ties that underlie a hybrid are widely regarded as having self-enforcing properties (Krippner and Alvarez 2007), the lack of a foreseeable future may represent a source of strain. As such, hybrids that are implemented within permanent organizations that possess a "shadow of the future" are uniquely positioned to both develop and maintain strong dyadic norms. For instance, such benefits may accrue to research organizations working under the aegis of the same pharmaceutical company or components suppliers working on upgrades to the next generation of high-technology products. Further, common ownership may in some instances serve as an important buffer. As noted, certain agency initiatives (e.g., 
monitoring) may in themselves be associated with negative consequences (e.g., agent reactance). However, to the extent that the larger organizational context legitimizes such practices, this risk may be mitigated (Williamson 1975).

There may also be inherent incompatibilities between the properties of a temporary organization and its larger context. For instance, temporary organizations frequently develop unique norms distinct from those of permanent organizations, and in some instances may even be purposely protected from the effects of a larger permanent organization (O'Connor and DeMartino 2006). Hence, the specific nature of the influence from a temporary marketing organization's larger context is not clear-cut. As a consequence, some firms choose to co-locate temporary organizations with the focal permanent firm while others intentionally put distance between them. For example, Walmart Labs works side-by-side with the Walmart Global eCommerce team to ensure seamless implementation of new ideas. By contrast, other firms intentionally set up "innovation outposts" located in distant technology clusters to enable involvement "in the tech community, without committing significant investment" (Solis et al. 2015, p. 6). A full-fledged theory of temporary organizations will require a more comprehensive specification of how organization-level mechanisms interact with particular aspects of a temporary organization's larger context to influence performance. It will also require a more finegrained analysis of temporary organization forms.

Structural Embeddedness. A second avenue for future research pertains to the interactions between a temporary organization's practices and its larger industry context. While our primary focus was on relational embeddedness between a principal and an agent, structural embeddedness - that is, "connections among mutual contacts" (Jones and Lichtenstein 2008; Wuyts and Van den Bulte 2012) - raises interesting questions. For instance, agents' industry reputations may serve (indirect) selection purposes in a network. On the face of it, the dense networks within 
which many temporary organizations operate may lend themselves well to reputation effects (Bechky 2006; Grabher 2004). At the same time, the inherent difficulty of monitoring individual agent effort undermines the disciplinary role of reputations. Conceivably, reputation effects associated with a temporary organization may be more strongly tied to relational than bespoke temporary organizational attributes. Future research could be directed towards (1) the key aspects of reputations in the context of temporary organizations, and (2) the extent to which the relevant attributes serve selection and enforcement purposes.

Multi-Level Relationships. Future research can usefully be directed towards exploring more complex relationships that may not readily fit the standard principal-agent model, or that may span multiple levels, involving upstream suppliers, producers, and even downstream customers. Consider first the former. Noticeably, some temporary organizations lack clear hierarchical structures and an independent authority to make decisions and enforce compliance. For instance, Sapsed and Salter (2004) note that the absence of a single executive owner (principal) of a global computing project led to lapses in problem-solving. Similarly, large government marketing projects often have multiple principals, including Congressional and White House committees, specific government offices, and executive departmental units (Moe 1987). This was apparent with the significant cost overruns that accompanied the development of the Healthcare.gov website - the portal through which U.S. citizens could compare health insurance plans under the 2010 Affordable Care Act. The coders brought in to save the product development process found themselves continually stifled by "tiers of people" across multiple government entities who, as one coder put it, were "managing developers at a distance" (Meyer 2015, p. 6). Even in such temporary organizations, the agency problems of hidden information and hidden action, and thus the organizational challenges of selection and enforcement, still prevail (Eggers and O'Leary 2009; Sapsed and Salter 2004). Differences exist, however, in the 
ways in which processes such as enforcement are carried out: although monitoring is a generic phenomenon, the nature of the monitoring process in temporary organizations with unclear hierarchical structures differs and calls for further enquiry.

Furthermore, a temporary organization may establish social or "communal" exchanges (Clark and Mils 1993) with downstream customers. For instance, for certain movies, entire “brand communities” (Muniz and O'Guinn 2001) have emerged. In Becker's (1982) terminology, customers become permanent members of certain "art worlds", and come to identify with the temporary organization itself. Similarly, social ties between the relevant parties in the IT industry blur the traditional boundaries between principals and agents (Kirsch et al. 2010). Managers of temporary marketing organization have started to exploit these relationships, for instance by incorporating customers' suggestions early in their product development efforts (Huston and Sakkab 2006) and by hiring them as agents. By doing so, they may be in a position to resolve both selection and enforcement problems.

Micro-level properties and processes. Another research avenue pertains to the micro-level structural characteristics of temporary organizations. For instance, in a similar fashion to permanent organizations, characteristics like size (Katz and Kahn 1978) may create organizational challenges which have selection and enforcement implications. Further, power and politics in temporary organizations provide a promising avenue of research. Kaplan and Orlikowski (2013) uncover the inherently political nature of temporary organizing, and McGivern et al. (2017) build on Granqvist and Gustafsson (2016) to demonstrate how the politics involving actors with different temporal orientations manifest themselves.

In general, we hope that our perspective on temporary marketing organizations will motivate further conceptual and empirical inquiry. We also hope that it will assist marketing managers in making informed choices on temporary organizations, and in matching 
organizational forms and task, time and team drivers. While the merging of economic and sociological perspectives that underlies our framework is "messy" (Kreps 1997), its payoffs may be considerable and add to our understanding of temporary marketing organizations. 
TABLE 1

\section{Organizational Forms}

\begin{tabular}{|c|c|c|c|c|c|}
\hline & & $\begin{array}{c}\text { Stand-Alone Temporary } \\
\text { Organization }\end{array}$ & Joint Venture & Start-up & Permanent Organization \\
\hline \multirow{2}{*}{ Time } & 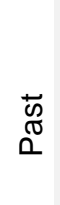 & $\begin{array}{l}\text { Absent } \\
\text { - No history of ties between } \\
\text { organizational members; only } \\
\text { industry level reputations } \\
\text { available }\end{array}$ & $\begin{array}{l}\text { Possible } \\
\text { - History of working } \\
\text { relationship determines joint } \\
\text { venture partner }\end{array}$ & $\begin{array}{l}\text { Absent } \\
\text { - Typically, no history of ties } \\
\text { between members }\end{array}$ & $\begin{array}{l}\text { Existing } \\
\text { - Existing members managed } \\
\text { within employment } \\
\text { relationship }\end{array}$ \\
\hline & 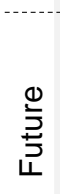 & $\begin{array}{l}\text { Absent } \\
\text { - Termination implied with task } \\
\text { completion }\end{array}$ & $\begin{array}{l}\text { Possible } \\
\text { - Formed with multiple projects } \\
\text { in mind }\end{array}$ & $\begin{array}{l}\text { Intended } \\
\text { - Organizational longevity and } \\
\text { growth are assumed }\end{array}$ & $\begin{array}{l}\text { Existing } \\
\text { - Organizational longevity is } \\
\text { assumed }\end{array}$ \\
\hline $\begin{array}{l}\text { Indicative } \\
\text { literature }\end{array}$ & & $\begin{array}{l}\text { Lundin and Söderholm (1995), } \\
\text { Engwall and Svensson (2004) }\end{array}$ & $\begin{array}{l}\text { Kogut (1988), Hennart (1988), } \\
\text { Gulati (1998) }\end{array}$ & $\begin{array}{l}\text { Carter, Gartner, and Reynolds } \\
(1996), \text { Brouthers and Brouthers } \\
(2000)\end{array}$ & $\begin{array}{l}\text { Williamson (1975), Cyert and } \\
\text { March (1963), March and Simon } \\
(1958)\end{array}$ \\
\hline Example & & $\begin{array}{l}\text { An organization that exists solely } \\
\text { to address a specific issue (i.e., } \\
\text { create a new product or service), } \\
\text { and is disbanded after the } \\
\text { completion of the task (e.g., app } \\
\text { developers for Healthcare.gov). }\end{array}$ & $\begin{array}{l}\text { An organization created by two or } \\
\text { more parties, characterized by } \\
\text { shared ownership, to combine } \\
\text { capabilities to address one or } \\
\text { more issues of joint interest. May } \\
\text { dissolve (e.g., Lion and } \\
\text { Heineken) or may become } \\
\text { permanent (e.g., Dow Corning) }\end{array}$ & $\begin{array}{l}\text { A newly created organization } \\
\text { designed to exploit a market } \\
\text { opportunity, with a minimum } \\
\text { viable product, service, or } \\
\text { platform and a scalable business } \\
\text { model (e.g., WeWork, Square, } \\
\text { Uptake) }\end{array}$ & $\begin{array}{l}\text { A limited liability organization with } \\
\text { (often public) established } \\
\text { ownership arrangements and } \\
\text { stable governance structures } \\
\text { (e.g., independent board and } \\
\text { management team) and ongoing } \\
\text { employment relations (e.g., IBM, } \\
\text { DuPont, Procter \& Gamble) }\end{array}$ \\
\hline
\end{tabular}


TABLE 2

Temporary Organization Forms

\begin{tabular}{|c|c|c|}
\hline Past & Temporary Organization Forms & Future \\
\hline $\begin{array}{l}\text { No shared history } \\
\text { - Lack of information on member } \\
\text { attributes } \\
\text { - Need for explicit selection }\end{array}$ & $\begin{array}{l}\text { Stand-alone } \\
\text { (e.g., a radical innovation project, a one- } \\
\text { off product launch event) }\end{array}$ & $\begin{array}{l}\text { No shadow of the future } \\
\text { - No inherent incentive for member } \\
\text { cooperation } \\
\text { - Need for explicit enforcement of } \\
\text { member effort to complete task }\end{array}$ \\
\hline $\begin{array}{l}\text { Direct history } \\
\text { - Direct observation and personal } \\
\text { - } \text { - Dyadic notion } \\
\text { - norms }\end{array}$ & $\begin{array}{c}\text { Hybrid } \\
\text { (e.g., feature film production, marketing } \\
\text { communications campaigns) }\end{array}$ & $\begin{array}{l}\text { Uncertain future } \\
\text { - Weak incentives for member } \\
\text { cooperation } \\
\text { - Need for explicit enforcement of } \\
\text { member effort to complete task }\end{array}$ \\
\hline $\begin{array}{l}\text { Shared organizational history } \\
\text { - Organization-level reputation } \\
\text { - Organization-level norms }\end{array}$ & $\begin{array}{l}\text { Fully embedded } \\
\text { (e.g., internal consulting unit, new } \\
\text { product development team) }\end{array}$ & $\begin{array}{l}\text { Shadow of the future } \\
\text { - Open-ended interaction of members } \\
\text { Explicit enforcement mechanisms } \\
\text { - Low-powered incentives } \\
\text { - Centralized monitoring of members }\end{array}$ \\
\hline
\end{tabular}




\section{Figure 1}

Conceptual Framework

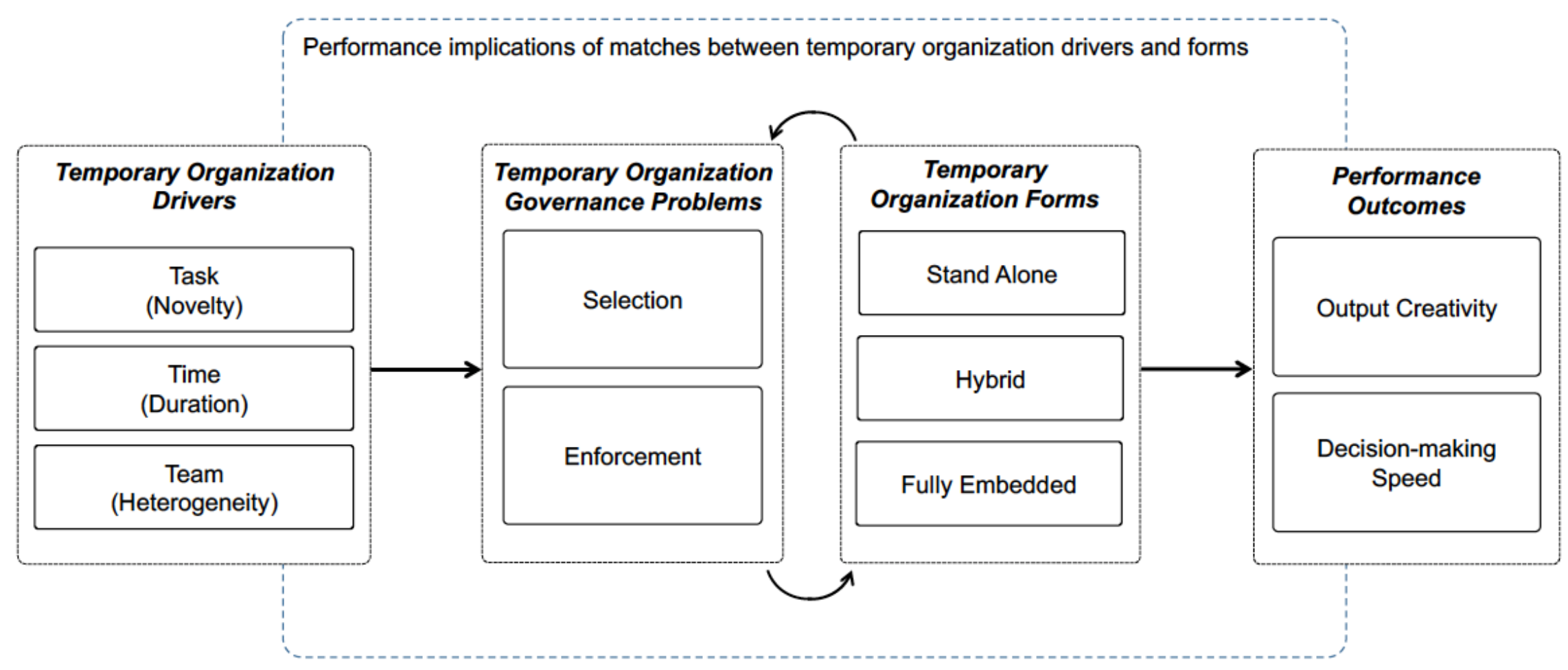




\section{References}

Aaronson, Matt, David Schaar, and Greg Mallory (2016), "Can Airplane OEMs Increase Their Share of Profits?," in BCG Perspectives: Boston Consulting Group.

Ahlbäck, Karin, Clemens Fahrbach, Monica Murarka, and Olli Salo (2017), "McKinsey Global Survey Results: How to create an agile organization," October).

Akerlof, George A. (1970), "The Market for "Lemons": Quality Uncertainty and the Market Mechanism," The Quarterly Journal of Economics, 84 (3), 488-500.

Akerlof, George A. and Rachel E. Kranton (2010), Identity Economics: How Identities Shape Our Work, Wages, and Well-Being. Princeton, NJ: Princeton University Press.

Arrow, Kenneth J. (1985), "The economics of agency," in Principals and Agents: The Structure of Business, John W. Pratt and Richard J. Zeclchauser, eds. Boston, MA: Harvard Business School Press.

Axelrod, Robert (1984), The Evolution of Cooperation. New York, NY: Basic Books.

Ayas, Karen and Nick Zeniuk (2001), "Project-Based Learning: Building Communities of Reflective Practitioners," Management Learning, 32 (1), 61-76.

Azoulay, Pierre and Josh Lerner (2013), "Technological Innovation and Organizations," in Handbook of Organizational Economics, R. Gibbons and J. Roberts, eds. Princeton, NJ:

Princeton University Press.

Bakker, Rene M., Robert J. DeFillippi, Andreas Schwab, and Jörg Sydow (2016), "Temporary Organizing: Promises, Processes, Problems," Organization Studies, 37 (12), 1703-19.

Bechky, Beth A. (2006), "Gaffers, Gofers, and Grips: Role-Based Coordination in Temporary Organizations," Organization Science, 17 (1), 3-21.

Becker, Howard S. (1982), Art Worlds. Berkeley, CA: University of California Press.

Bennis, Warren (1965), "Beyond bureaucracy," Trans-action, 2 (5), 31-35.

Bergen, Mark, Shantanu Dutta, and Orville C. Walker, Jr. (1992), "Agency Relationships in Marketing: A Review of the Implications and Applications of Agency and Related Theories," Journal of Marketing, 56 (3), 1-24.

Blair, Helen, Susan Grey, and Keith Randle (2001), "Working in film - Employment in a project based industry," Personnel Review, 30 (2), 170-85. 
Blau, Peter M. (1977), "A Macrosociological Theory of Social Structure," American Journal of Sociology, 83 (1), 26-54.

Bonacich, Phillip (1987), "Power and Centrality: A Family of Measures," American Journal of Sociology, 92 (5), 1170-82.

Brehm, Jack W. (1966), A Theory of Psychological Reactance. New York, NY: Academic Press.

Brouthers, Keith D. and Lance Eliot Brouthers (2000), "Acquisition or greenfield start-up?

Institutional, cultural and transaction cost influences," Strategic Management Journal, 21 (1), 8997.

Brown, Shona L. and Kathleen M. Eisenhardt (1995), "Product Development: Past Research, Present Findings, and Future Directions," Academy of Management Review, 20 (2), 343-78.

Bstieler, Ludwig and Martin Hemmert (2010), "Increasing Learning and Time Efficiency in Interorganizational New Product Development Teams," Journal of Product Innovation Management, 27 (4), 485-99.

Burke, Catriona M and Michael J Morley (2016), "On temporary organizations: A review, synthesis and research agenda," Human Relations, 69 (6), 1235-58.

Cao, Zhi and Fabrice Lumineau (2015), "Revisiting the interplay between contractual and relational governance: A qualitative and meta-analytic investigation," Journal of Operations Management, 33, 15-42.

Carter, Nancy M., William B. Gartner, and Paul D. Reynolds (1996), "Exploring start-up event sequences," Journal of Business Venturing, 11 (3), 151-66.

Casciaro, Tiziana and Miguel Sousa Lobo (2005), "Competent jerks, lovable fools, and the formation of social networks," Harvard business review, 83 (6), 92-99.

Cattani, Gino and Simone Ferriani (2008), "A Core/Periphery Perspective on Individual Creative Performance: Social Networks and Cinematic Achievements in the Hollywood Film Industry," Organization Science, 19 (6), 824-44.

Caves, Richard E. (2003), "Contracts between Art and Commerce," The Journal of Economic Perspectives, 17 (2), 73-84.

---- (2000), Creative Industries: Contracts between Art and Commerce. Cambridge, MA: Harvard University Press.

Chandy, Rajesh, Brigitte Hopstaken, O. M. Narasimhan, and Jaideep Prabhu (2006), "From Invention to Innovation: Conversion Ability in Product Development," Journal of Marketing Research (JMR), 43 (3), 494-508. 
Chatman, Jennifer A. (1991), "Matching People and Organizations: Selection and Socialization in Public Accounting Firms," Administrative Science Quarterly, 36 (3), 459-84.

Che, Yeon-Koo and Seung-Weon Yoo (2001), "Optimal Incentives for Teams," American Economic Review, 91 (3), 525-41.

Chen, Katherine K. (2009), Enabling Creative Chaos: The Organization behind the Burning Man Event. Chicago, IL: University of Chicago Press.

Child, John and Rita Gunther McGrath (2001), "Organizations Unfettered: Organizational Form in an Information-Intensive Economy," The Academy of Management Journal, 44 (6), 1135-48.

Chisholm, Darlene C. (1997), "Profit-Sharing versus Fixed-Payment Contracts: Evidence from the Motion Pictures Industry," Journal of Law, Economics, \& Organization, 13 (1), 169-201.

Clark, Kim B. and Takahiro Fujimoto (1991), Product development performance: Strategy, organization, and management in the world auto industry. Cambridge, MA: Harvard Business Press.

Clark, Margaret S. and Judson Mils (1993), "The Difference between Communal and Exchange Relationships: What it is and is Not," Personality and Social Psychology Bulletin, 19 (6), 684-91.

Coase, Ronald H. (1937), "The Nature of the Firm," Economica, 4 (16), 386-405.

Corts, Kenneth S. and Jasjit Singh (2004), "The Effect of Repeated Interaction on Contract Choice: Evidence from Offshore Drilling," Journal of Law Economics \& Organization, 20 (1), 230-60.

Cremer, Jacques (1986), "Cooperation in Ongoing Organizations," Quarterly Journal of Economics, 101 (1), 33-49.

Cyert, Richard M. and James. G. March (1963), A Behavioral Theory of the Firm. Englewood Cliffs, NJ: Prentice Hall.

Daskalaki, Maria (2010), "Building 'Bonds' and 'Bridges': Linking Tie Evolution and Network Identity in the Creative Industries," Organization Studies, 31 (12), 1649-66.

Davies, Andrew and Michael Hobday (2005), The business of projects: managing innovation in complex products and systems: Cambridge University Press.

Day, George S. (1994), "The Capabilities of Market-Driven Organizations," Journal of Marketing, 58 (4), 37-52.

Deci, Edward L., Richard Koestner, and Richard M. Ryan (1999), "A meta-analytic review of experiments examining the effects of extrinsic rewards on intrinsic motivation," Psychological bulletin, 125 (6), 627-68. 
Demsetz, Harold (1988), "The Theory of the Firm Revisited," Journal of Law, Economics, \& Organization, 4 (1), 141-61.

Dewar, Robert D. and Jane E. Dutton (1986), "The Adoption of Radical and Incremental Innovations: An Empirical Analysis," Management Science, 32 (11), 1422-33.

Dougherty, Deborah and C. Helen Takacs (2004), "Team play: Heedful interrelating as the boundary for innovation," Long Range Planning, 37 (6), 569-90.

Durkheim, Emile (1933), The Division of Labor in Society. London, UK: Macmillan.

Dwyer, F. Robert, Paul H. Schurr, and Sejo Oh (1987), "Developing Buyer-Seller Relationships," Journal of Marketing, 51 (2), 11-27.

Eggers, William D. and John O'Leary (2009), If We Can Put a Man on the Moon: Getting Big Things Done in Government. Boston, MA: Harvard Business Press.

Eisenhardt, Kathleen and Behna N. Tabrizi (1995), "Accelerating adaptive processes: product innovation in the global computer industry," Administrative Science Quarterly, 40, 84+.

Engwall, Mats and Charlotta Svensson (2004), "Cheetah teams in product development: the most extreme form of temporary organization?," Scandinavian journal of management, 20 (3), 297 317.

Fang, Eric (2008), "Customer Participation and the Trade-Off Between New Product Innovativeness and Speed to Market," Journal of Marketing, 72 (4), 90-104.

Faulkner, Robert R. and Andy B. Anderson (1987), "Short-Term Projects and Emergent Careers: Evidence from Hollywood," American Journal of Sociology, 92 (4), 879-909.

Flyvbjerg, Bent (2011), "Over Budget, Over Time, Over and Over Again," in The Oxford Handbook of Project Management, Peter W. G. Morris and Jeffrey K. Pinto and Jonas Söderlund, eds. Oxford, UK: Oxford University Press.

Gann, David M. and Ammon J. Salter (2000), "Innovation in project-based, service-enhanced firms: the construction of complex products and systems," Research Policy, 29 (7-8), 955-72.

Ghosh, Mrinal and George John (2012), "Progress and Prospects for Governance Value Analysis in Marketing: When Porter Meets Williamson," in Handbook of Business-to-Business Marketing, Rajdeep Grewal and Gary L. Lilien, eds. Northampton, MA: Edward Elgar.

---- (2005), "Strategic Fit in Industrial Alliances: An Empirical Test of Governance Value Analysis.," Journal of Marketing Research, 42 (3), 346-57.

Goodman, Richard A. and Lawrence P. Goodman (1976), "Some Management Issues in Temporary Systems: A Study of Professional Development and Manpower - The Theater Case," Administrative Science Quarterly, 21 (3), 494-501. 
Grabher, Gernot (2002), "Fragile Sector, Robust Practice: Project Ecologies in New Media," Environment and Planning A, 34 (11), 1911-26.

---- (2004), "Temporary Architectures of Learning: Knowledge Governance in Project Ecologies," Organization Studies, 25 (9), 1491-514.

Gralpois, Bruno (2010), Agency Mania: Harnessing the Madness of Client/Agency Relationships for High-Impact Results: Publish Green.

Granovetter, Mark (1992), "Economic Institutions as Social Constructions: A Framework for Analysis," Acta Sociologica, 35 (1), 3-11.

---- (2005), "The Impact of Social Structure on Economic Outcomes," Journal of Economic Perspectives, 19 (1), 33-50.

---- (1973), "The Strength of Weak Ties," American Journal of Sociology, 78 (6), 1360-80.

Granqvist, Nina and Robin Gustafsson (2016), "Temporal Institutional Work," Academy of Management Journal, 59 (3), 1009-35.

Grant, Robert M. (1996), "Toward a Knowledge-Based Theory of the Firm," Strategic Management Journal, 17 (S2), 109-22.

Greenwood, Royston and Laura Empson (2003), "The Professional Partnership: Relic or Exemplary Form of Governance?," Organization Studies, 24 (6), 909-33.

Griffin, Abbie (1997), "The Effect of Project and Process Characteristics on Product Development Cycle Time," Journal of Marketing Research, 34 (1), 24-35.

Grossman, Sanford J. and Oliver D. Hart (1983), "An Analysis of the Principal-Agent Problem," Econometrica, 51 (1), 7-45.

Groysberg, Boris, Linda-Eling Lee, and Ashish Nanda (2008), "Can They Take It with Them? The Portability of Star Knowledge Workers' Performance," Management Science, 54 (7), 121330.

Grugulis, Irena and Dimitrinka Stoyanova (2012), "Social Capital and Networks in Film and TV: Jobs for the Boys?," Organization Studies, 33 (10), 1311-31.

Gulati, Ranjay (1998), "Alliances and networks," Strategic Management Journal, 19 (4), 293317.

Gulati, Ranjay and Martin Gargiulo (1999), "Where Do Interorganizational Networks Come From?," American Journal of Sociology, 104 (5), 1439-93. 
Gulati, Ranjay, Dovev Lavie, and Harbir Singh (2009), "The nature of partnering experience and the gains from alliances," Strategic Management Journal, 30 (11), 1213-33.

Gulati, Ranjay, Franz Wohlgezogen, and Pavel Zhelyazkov (2012), "The Two Facets of Collaboration: Cooperation and Coordination in Strategic Alliances," The Academy of Management Annals, 6 (1), 531-83.

Heide, Jan B. and Anne S. Miner (1992), "The Shadow of the Future: Effects of Anticipated Interaction and Frequency of Contact on Buyer-Seller Cooperation," Academy of Management Journal, 35 (2), 265-91.

Heide, Jan B., Kenneth H. Wathne, and Aksel I. Rokkan (2007), "Interfirm Monitoring, Social Contracts, and Relationship Outcomes," Journal of Marketing Research, 44 (3), 425-33.

Hennart, Jean-Francois (1988), "A transaction costs theory of equity joint ventures," Strategic Management Journal, 9 (4), 361-74.

Holmstrom, Bengt R. and Paul Milgrom (1991), "Multitask Principal-Agent Analyses: Incentive Contracts, Asset Ownership, and Job Design," Journal of Law, Economics, \& Organization, 7 , 24-52.

Holmstrom, Bengt R. and Jean Tirole (1989), "The theory of the firm," in Handbook of industrial organization, Vol. 1.

Horwitz, Sujin K. and Irwin B. Horwitz (2007), "The Effects of Team Diversity on Team Outcomes: A Meta-Analytic Review of Team Demography," Journal of Management, 33 (6), 987-1015.

Huckman, Robert S. and Gary P. Pisano (2006), "The Firm Specificity of Individual Performance: Evidence from Cardiac Surgery," Management Science, 52 (4), 473-88.

Huston, Larry and Nabil Sakkab (2006), "Connect and Develop," Harvard Business Review, 84 (3), 58-66.

Ibert, Oliver (2004), "Projects and firms as discordant complements: organisational learning in the Munich software ecology," Research Policy, 33 (10), 1529-46.

Ippolito, Pauline M. (1990), "Bonding and Nonbonding Signals of Product Quality," The Journal of Business, 63 (1), 41-60.

Jacobides, Michael G. and David C. Croson (2001), "Information Policy: Shaping the Value of Agency Relationships," The Academy of Management Review, 26 (2), 202-23.

Jacobsson, Mattias, Thommie Burström, and Timothy L. Wilson (2013), "The role of transition in temporary organizations: linking the temporary to the permanent," International Journal of Managing Projects in Business, 6 (3), 576-86. 
Jap, Sandy D. and Shankar Ganesan (2000), "Control Mechanisms and the Relationship Life Cycle: Implications for Safeguarding Specific Investments and Developing Commitment," Journal of Marketing Research, 37 (2), 227-45.

John, George (1984), "An Empirical investigation of Some Antecedents of Opportunism in a Marketing Channel," Journal of Marketing Research, 21 (3), 278-89.

Jones, Candace and Benyamin B. Lichtenstein (2008), "Temporary Inter-organizational Projects: How Temporal and Social Embeddedness Enhance Coordination and Manage Uncertainty," in Oxford Handbook of Inter-Organizational Relations, Steve Cropper and Chris Huxham and Mark Ebers and Peter S. Ring, eds. London, UK: Oxford University Press.

Kaplan, Sarah and Wanda J. Orlikowski (2013), "Temporal Work in Strategy Making," Organization Science, 24 (4), 965-95.

Katz, Daniel and Robert Louis Kahn (1978), The social psychology of organizations. New York: Wiley.

Kessler, Sarah (2017), "Who Needs a Firm?," Quartz (13 July), [available at https://qz.com/1027606].

Kirmani, Amna and Akshay R. Rao (2000), "No Pain, No Gain: A Critical Review of the Literature on Signaling Unobservable Product Quality," Journal of Marketing, 64 (2), 66-79.

Kirsch, Laurie J., Dong-Gil Ko, and Mark H. Haney (2010), "Investigating the Antecedents of Team-Based Clan Control: Adding Social Capital as a Predictor," Organization Science, 21 (2), 469-89.

Kogut, Bruce (1988), "Joint ventures: Theoretical and empirical perspectives," Strategic Management Journal, 9 (4), 319-32.

Krasnikov, Alexander and Satish Jayachandran (2008), "The Relative Impact of Marketing, Research-and-Development, and Operations Capabilities on Firm Performance," Journal of Marketing, 72 (4), 1-11.

Kreps, David M. (1997), "The Interaction between Norms and Economic Incentives: Intrinsic Motivation and Extrinsic Incentives," in American Economic Association Papers and Proceedings Vol. 87.

Krippner, Greta R. and Anthony S. Alvarez (2007), "Embeddedness and the Intellectual Projects of Economic Sociology," Annual Review of Sociology, 33 (1), 219-40.

Kumar, Alok, Jan B. Heide, and Kenneth H. Wathne (2011), "Performance Implications of Mismatched Governance Regimes Across External and Internal Relationships," Journal of Marketing, 75 (2), 1-17. 
Lenfle, Sylvain and Christoph Loch (2010), "Lost Roots: How Project Management Came to Emphasize Control Over Flexibility and Novelty," California Management Review, 53 (1), 32 55.

Levitt, Raymond E., Jan Thomsen, Tore R. Christiansen, John C. Kunz, Yan Jin, and Clifford Nass (1999), "Simulating Project Work Processes and Organizations: Toward a MicroContingency Theory of Organizational Design," Management Science, 45 (11), 1479-95.

Lundin, Rolf A., Niklas Arvidsson, Tim Brady, Eskil Ekstedt, Christophe Midler, and Jörg Sydow (2015), Managing and Working in Project Society. Cambridge, UK: Cambridge University Press.

Lundin, Rolf A. and Anders Söderholm (1995), "A theory of the temporary organization," Scandinavian Journal of Management, 11 (4), 437-55.

Macneil, Ian R. (1980), The New Social Contract, An Inquiry into Modern Contractual Relations. Newhaven, CT: Yale University Press.

Manning, Stephan and Jörg Sydow (2011), "Projects, paths, and practices: sustaining and leveraging project-based relationships," Industrial and Corporate Change, 20 (5), 1369-402.

March, James G. (1995), "The Future, Disposable Organizations and the Rigidities of Imagination," Organization, 2 (3-4), 427-40.

March, James and Herbert Simon (1958), Organizations. New York: Wiley Co.

McDonald, Michael L. and James D. Westphal (2003), "Getting by with the Advice of Their Friends: CEOs' Advice Networks and Firms' Strategic Responses to Poor Performance," Administrative Science Quarterly, 48 (1), 1-32.

McGivern, Gerry, Sue Dopson, Ewan Ferlie, Michael Fischer, Louise Fitzgerald, Jean Ledger, and Chris Bennett (2017), "The Silent Politics of Temporal Work: A Case Study of a Management Consultancy Project to Redesign Public Health Care," Organization Studies, First published date: July-14-2017, 0170840617708004.

Meyer, Robinson (2015), "The Secret Startup That Saved the Worst Website in America," in The Atlantic Vol. July, 9.

Meyerson, Debra, Karl E. Weick, and Roderick M. Kramer (1996), "Swift Trust and Temporary Groups," in Trust in Organizations: Frontiers of Theory and Research, Tom R. Tyler and Roderick M. Kramer, eds. Thousand Oaks: Sage Publications.

Mishra, Debi Prasad, Jan B. Heide, and G. Cort Stanton (1998), "Information asymmetry and levels of agency relationships," Journal of Marketing Research, 35 (3), 277-95.

Moe, Terry M. (1987), "An Assessment of the Positive Theory of 'Congressional Dominance'," Legislative Studies Quarterly, 12 (4), 475-520. 
Möller, Kristian and Arto Rajala (1999), "Organizing Marketing in Industrial High Tech Firms: The Role of Internal Marketing Relationships," Industrial Marketing Management, 28 (5), 52135 .

Moorman, Christine and George S. Day (2016), "Organizing for Marketing Excellence," Journal of Marketing, 80 (6), 6-35.

Muniz, Jr., Albert M. and Thomas C. O'Guinn (2001), "Brand Community," Journal of Consumer Research, 27 (4), 412-32.

Myshko, Denise (2014), "New Models for Academic Partnerships," in PharmaVOICE Vol. October.

Nohria, Nitin (1992), "Information and Search in the Creation of New Business Ventures: The Case of the 128 Group," in Networks and Organizations: Structure, Form, and Action, Nitin Nohria and Robert G. Eccles, eds. Boston, MA: Harvard Business School Press.

O'Connor, Gina Colarelli and Richard DeMartino (2006), "Organizing for Radical Innovation: An Exploratory Study of the Structural Aspects of RI Management Systems in Large Established Firms," Journal of Product Innovation Management, 23 (6), 475-97.

Ojansivu, Ilkka, Kimmo Alajoutsijärvi, and Jari Salo (2013), "The development of post-project buyer-seller interaction in service-intensive projects," Industrial Marketing Management, 42 (8), $1318-27$.

Orr, Kevin (2014), "Local Government Chief Executives' Everyday Hauntings: Towards a Theory of Organizational Ghosts," Organization Studies, 35 (7), 1041-61.

Osterloh, Margit and Bruno S. Frey (2000), "Motivation, Knowledge Transfer, and Organizational Forms," Organization Science, 11 (5), 538-50.

Ouchi, William G. (1980), "Markets, Bureaucracies, and Clans," Administrative Science Quarterly, 25 (1), 129-41.

Packard, Grant, Anocha Aribarg, Jehoshua Eliashberg, and Natasha Z. Foutz (2016), "The role of network embeddedness in film success," International Journal of Research in Marketing, 33 (2), $328-42$.

Packendorff, Johann (1995), "Inquiring into the temporary organization: New directions for project management research," Scandinavian Journal of Management, 11 (4), 319-33.

Parmigiani, Anne and Miguel Rivera-Santos (2011), "Clearing a Path Through the Forest: A Meta-Review of Interorganizational Relationships," Journal of Management, 37 (4), 1108-36. 
Perretti, Fabrizio and Giacomo Negro (2007), "Mixing genres and matching people: a study in innovation and team composition in Hollywood," Journal of Organizational Behavior, 28 (5), 563-86.

Pfohl, Hans-Christian and Hans Peter Buse (2000), "Inter-organizational logistics systems in flexible production networks: An organizational capabilities perspective," International Journal of Physical Distribution \& Logistics Management, 30 (5), 388-408.

Reagans, Ray, Ezra Zuckerman, and Bill McEvily (2004), "How to Make the Team: Social Networks vs. Demography as Criteria for Designing Effective Teams," Administrative Science Quarterly, 49 (1), 101-33.

Rindfleisch, Aric and Christine Moorman (2001), "The Acquisition and Utilization of Information in New Product Alliances: A Strength-of-Ties Perspective," Journal of Marketing, 65 (2), 1-18.

Roth, George and Art Kleiner (2000), Car Launch: The Human Side of Managing Change. New York: Oxford University Press.

Rowley, Tim, Dean Behrens, and David Krackhardt (2000), "Redundant governance structures: an analysis of structural and relational embeddedness in the steel and semiconductor industries," Strategic Management Journal, 21 (3), 369-86.

Sapsed, Jonathan and Ammon Salter (2004), "Postcards from the Edge: Local Communities, Global Programs and Boundary Objects," Organization Studies, 25 (9), 1515-34.

Scheiber, Noam (2017), "The Pop-Up Employer," in The New York Times. July 12 ed.

Schreyögg, Georg and Jörg Sydow (2010), "Crossroads-organizing for fluidity? Dilemmas of new organizational forms," Organization Science, 21 (6), 1251-62.

Schwab, Andreas and Anne S. Miner (2008), "Learning in Hybrid-Project Systems: The Effects of Project Performance on Repeated Collaboration," Academy of Management Journal, 51 (6), 1117-49.

Shenhar, Aaron J. (2001), "Contingent management in temporary, dynamic organizations: The comparative analysis of projects," The Journal of High Technology Management Research, 12 (2), 239-71.

Shenhar, Aaron J., Vered Holzmann, Benjamin Melamed, and Yao Zhao (2016), "The Challenge of Innovation in Highly Complex Projects: What Can We Learn from Boeing's Dreamliner Experience?," Project Management Journal, 47 (2), 62-78.

Solis, Brian, Jerome Buvat, K. V. J. Subrahmanyam, and Rishi Raj Singh (2015), "The Innovation Game: Why and How Businesses are Investing in Innovation Centers." Paris: Capgemini Consulting. 
Spence, Michael (1973), "Job Market Signaling," The Quarterly Journal of Economics, 87 (3), 355-74.

Starkey, Ken, Christopher Barnatt, and Sue Tempest (2000), "Beyond Networks and Hierarchies: Latent Organizations in the U.K. Television Industry," Organization Science, 11 (3), 299-305.

Stuart, Toby E. (1998), "Network Positions and Propensities to Collaborate: An Investigation of Strategic Alliance Formation in a High-Technology Industry," Administrative Science Quarterly, 43 (3), 668-98.

Sydow, Jörg (2017), "Temporary Organizing - The End of Organizations as We Know Them?," Rutgers Business Review, 2 (2), 199-204.

Tadena, Nathalie (2016), "Average Tenure Among Chief Marketing Officers Slips," in Wall Street Journal. New York.

Tax, Stephen S., David McCutcheon, and Ian F. Wilkinson (2013), "The Service Delivery Network (SDN):A Customer-Centric Perspective of the Customer Journey," Journal of Service Research, 16 (4), 454-70.

Taylor, John E. and Raymond Levitt (2007), "Innovation Alignment and Project Network Dynamics: An Integrative Model for Change," Project Management Journal, 38 (3), 22-35.

Teece, David J. (2003), "Expert talent and the design of (professional services) firms," Industrial and Corporate Change, 12 (4), 895-916.

Thompson, James D. (1967), Organizations in Action. New York: McGraw-Hill.

Tuli, Kapil R., Ajay K. Kohli, and Sundar G. Bharadwaj (2007), "Rethinking Customer Solutions: From Product Bundles to Relational Processes," Journal of Marketing, 71 (3), 1-17.

Turner, J. Rodney and Ralf Müller (2003), "On the nature of the project as a temporary organization," International Journal of Project Management, 21 (1), 1-8.

Ulset, Svein (1996), "R\&D outsourcing and contractual governance: An empirical study of commercial R\&D projects," Journal of Economic Behavior \& Organization, 30 (1), 63-82.

Uzzi, Brian (1997), "Social Structure and Competition in Interfirm Networks: The Paradox of Embeddedness," Administrative Science Quarterly, 42 (1), 35-67.

Vargo, Stephen L. and Robert F. Lusch (2008), "From goods to service(s): Divergences and convergences of logics," Industrial Marketing Management, 37 (3), 254-59.

von Nordenflycht, Andrew (2010), "What Is a Professional Service Firm? toward a Theory and Taxonomy of Knowledge-Intensive Firms," The Academy of Management Review, 35 (1), 15574. 
Williamson, Oliver E. (1975), Markets and Hierarchies: Analysis and Antitrust Implications. New York: The Free Press.

Wu, Yuhong, Sridhar Balasubramanian, and Vijay Mahajan (2004), "When Is a Preannounced New Product Likely to Be Delayed?," Journal of Marketing, 68 (2), 101-13.

Wuyts, Stefan and Inge Geyskens (2005), "The Formation of Buyer-Supplier Relationships: Detailed Contract Drafting and Close Partner Selection," Journal of Marketing, 69 (4), 103-17.

Wuyts, Stefan and Christophe Van den Bulte (2012), "Network governance," in Handbook on Business to Business Marketing, Gary L. Lilien and Rajdeep Grewal, eds. Cheltenham, UK: Edward Elgar.

Zenger, Todd R. (1994), "Explaining Organizational Diseconomies of Scale in R\&D: Agency Problems and the Allocation of Engineering Talent, Ideas, and Effort by Firm Size," Management Science, 40 (6), 708-29. 